\title{
Featured Artist: Gabriella Marcarelli
}

New College of Florida

We are thrilled to share five pieces of art by the talented Gabriella Marcarelli, as well as her artistic rationale for her work.

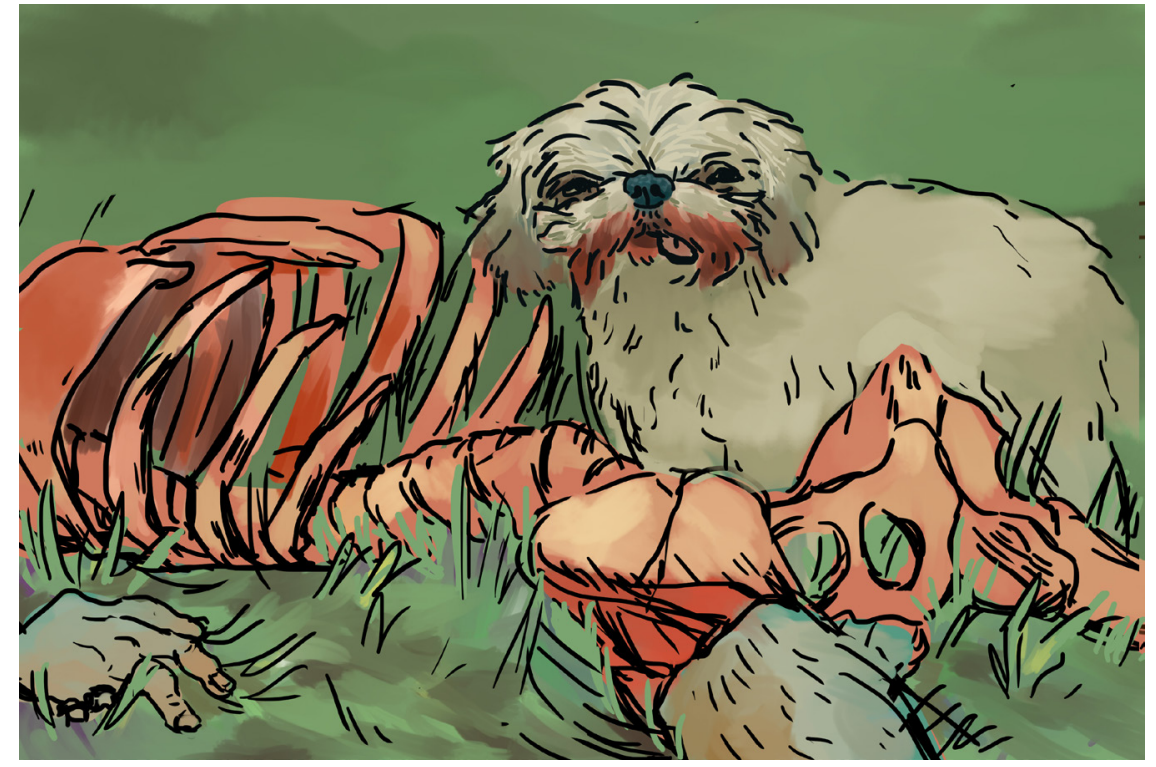

"Treat"

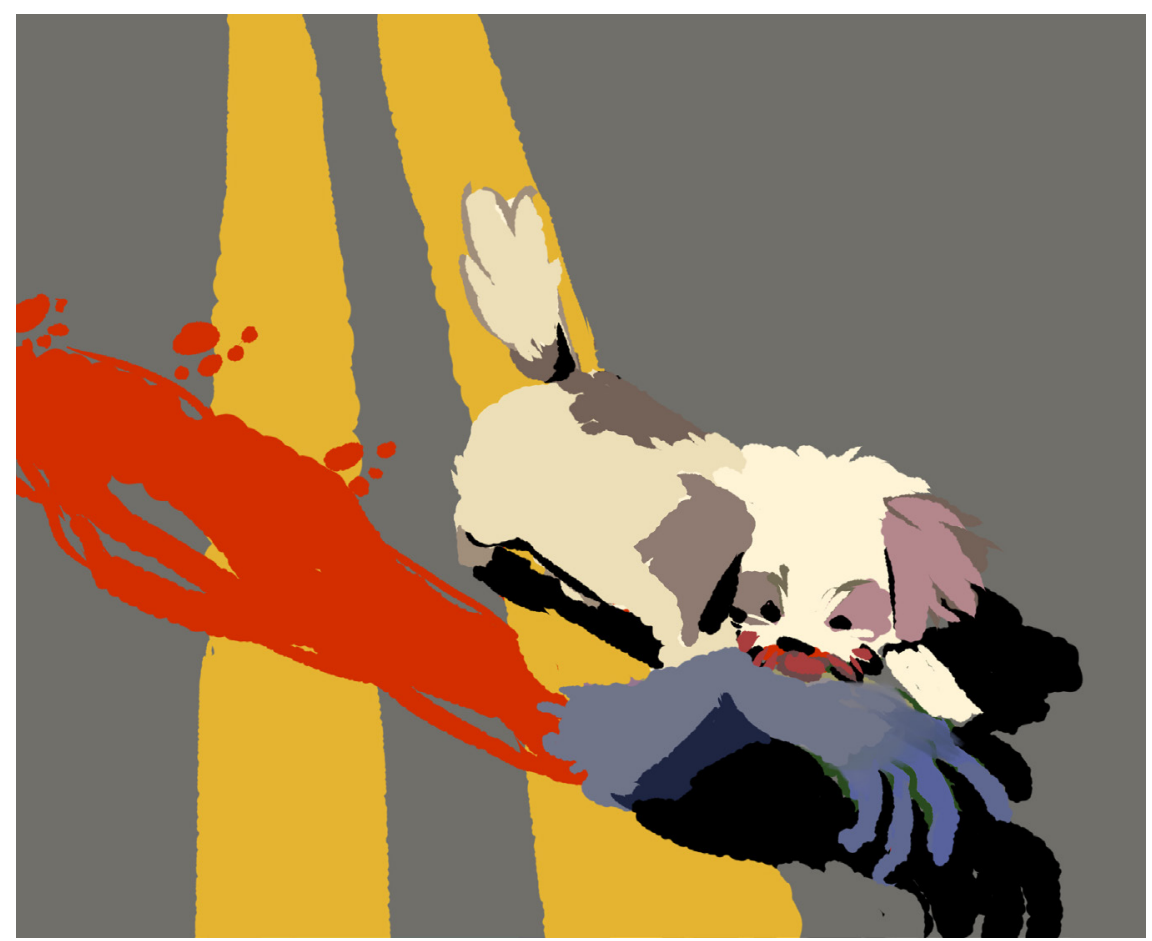

"People Food"
In this post-apocalyptic world, Shih Tzus are apex predators, and humans are their main prey.

I think that post-apocalyptic narratives are often too antropocentric-sometimes even devoid of any living beings besides humans. As such they often also rely on cannibalism and murder to epitomize the status of morals in a new, lawless world. Shih Tzus have always been lawless creatures, though we see them as not the predator animals they are, but rather our adorable and lovable companions. There is absolutely an expected dissonance between seeing their cute, dopey faces covered in blood and human remains. 


\section{MARCARELLI}

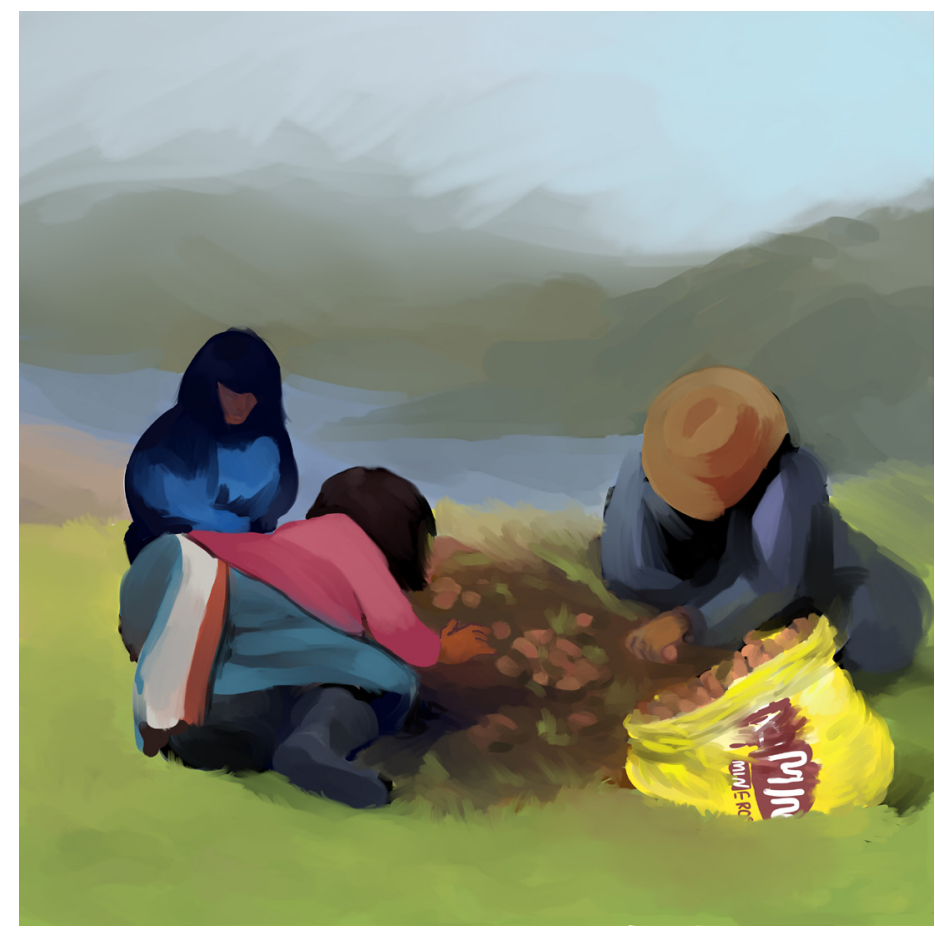

\section{"Pallaqueras"}

Often stories of the post-apocalypse center on a dilapidated American landscape that is void of life and morals. However, for these three pieces, I tried to imagine how the mining town of La Rinconada, Peru would look in a post-apocalyptic setting. The

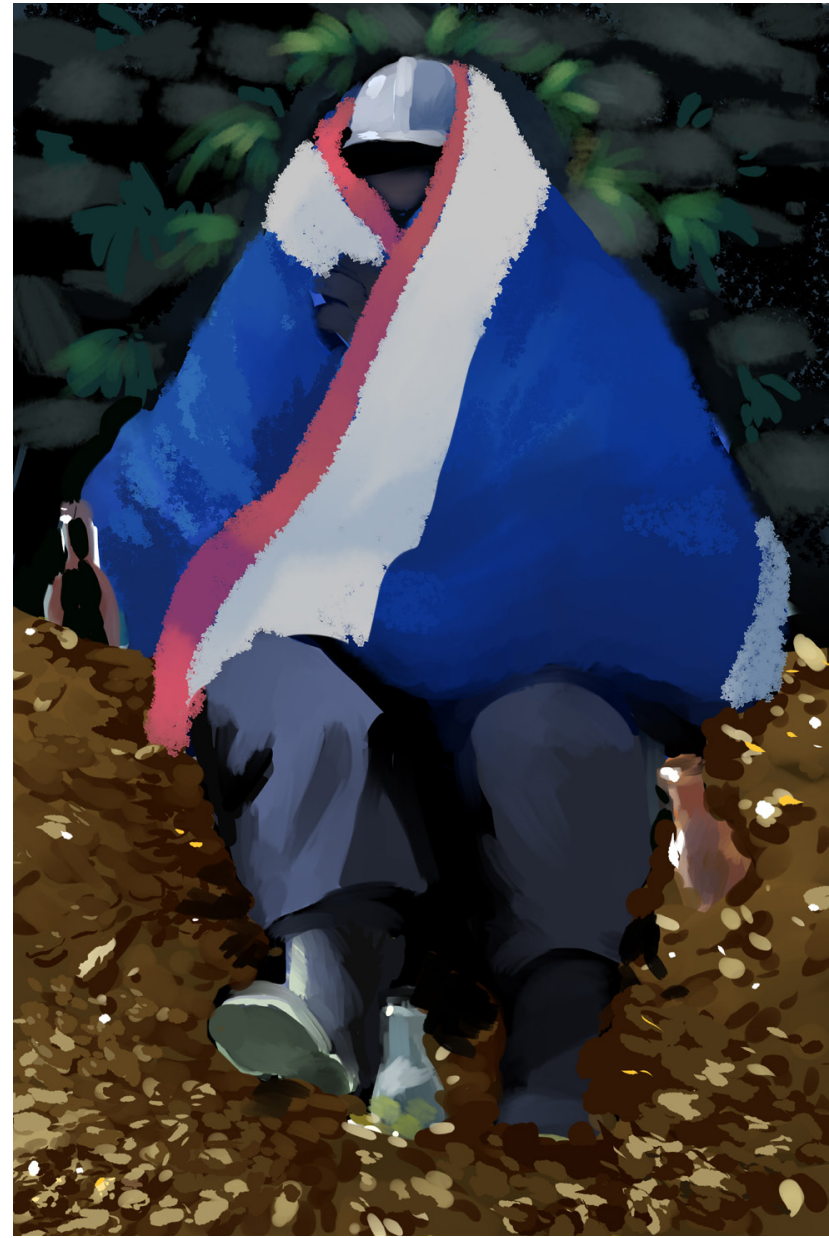

"Mamacha" present-day, economic climate of Peru forces its citizens, mainly its indigenous citizens, to seek work in the inhumane and inhospitable gold mines of La Rinconada. Currently, the exploitation of miners and land at the hands of the gold industry has led this town to become nearly postapocalyptic. So perhaps the death of the gold industry via the apocalypse would allow for a sort of rebirth; through a collective effort, the town could abandon the mines and foster plant life and agriculture to sustain themselves and live on for themselves and those lost

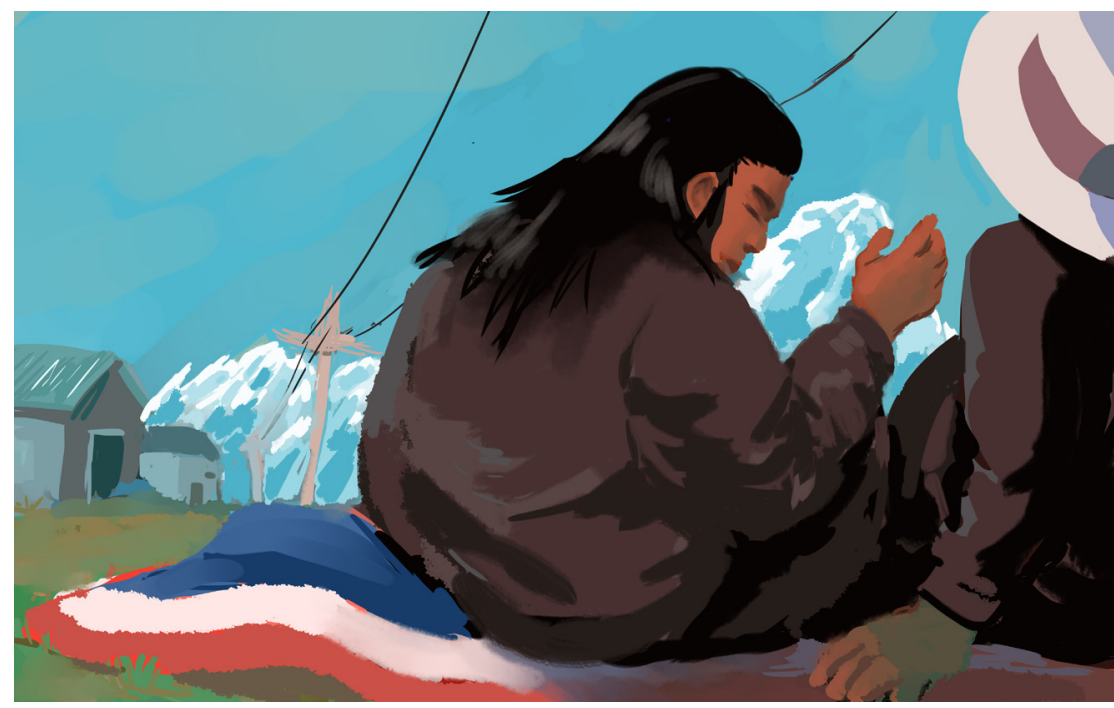

"El Despertar" to the apocalypse. 